\title{
International management platform for children's interstitial lung disease (chILD-EU)
}

\author{
Matthias Griese, ${ }^{1}$ Elias Seidl, ${ }^{1}$ Meike Hengst, ${ }^{1}$ Simone Reu, ${ }^{2}$ Hans Rock, ${ }^{3}$ \\ Gisela Anthony, ${ }^{3}$ Nural Kiper, ${ }^{4}$ Nagehan Emiralioğlu, ${ }^{4}$ Deborah Snijders, ${ }^{5}$ \\ Lutz Goldbeck, ${ }^{6}$ Reiner Leidl, ${ }^{7}$ Julia Ley-Zaporozhan, ${ }^{8}$ Ingrid Krüger-Stollfuss, ${ }^{8}$ \\ Birgit Kammer, ${ }^{8}$ Traudl Wesselak, ${ }^{1}$ Claudia Eismann, ${ }^{1}$ Andrea Schams, ${ }^{1}$ \\ Doerthe Neuner, ${ }^{1}$ Morag MacLean, ${ }^{9}$ Andrew G Nicholson, ${ }^{10}$ McCann Lauren, ${ }^{11}$ \\ Annick Clement, ${ }^{12}$ Ralph Epaud, ${ }^{12}$ Jacques de Blic, ${ }^{12}$ Michael Ashworth, ${ }^{13}$ \\ Paul Aurora, ${ }^{13}$ Alistair Calder, ${ }^{13}$ Martin Wetzke, ${ }^{14}$ Matthias Kappler, $^{1}$ \\ Steve Cunningham, ${ }^{9}$ Nicolaus Schwerk, ${ }^{14}$ Andy Bush, ${ }^{10,11}$ and the other chILD-EU \\ collaborators
}

\begin{abstract}
- Additional materials for this paper are available online. To view please visit the journal (http://dx.doi.org/ 10.1136/thoraxinl-2017210519)
\end{abstract}

For numbered affiliations see end of article.

\section{Correspondence to} Dr Matthias Griese, Department of Pediatric Pneumology, Dr von Hauner Children's Hospital, Ludwig-Maximilians-University, German Center for Lung Research, Munich 80337, Germany; matthias.griese@ med.uni-muenchen.de

SC, NS and AB contributed equally.

Contact the chILD-EU platform under www.childeu.net

Received 13 May 2017 Revised 31 August 2017 Accepted 18 September 2017 Published Online First 22 October 2017

\begin{abstract}
Background Children's interstitial lung diseases (chILD) cover many rare entities, frequently not diagnosed or studied in detail. There is a great need for specialised advice and for internationally agreed subclassification of entities collected in a register. Our objective was to implement an international management platform with independent multidisciplinary review of cases at presentation for long-term follow-up and to test if this would allow for more accurate diagnosis. Also, quality and reproducibility of a diagnostic subclassification system were assessed using a collection of 25 complex chILD cases.
\end{abstract}

Methods A web-based chILD management platform with a registry and biobank was successfully designed and implemented.

Results Over a 3-year period, 575 patients were included for observation spanning a wide spectrum of chILD. In 346 patients, multidisciplinary reviews were completed by teams at five international sites (Munich $51 \%$, London 12\%, Hannover 31\%, Ankara 1\% and Paris $5 \%$ ). In $13 \%$, the diagnosis reached by the referring team was not confirmed by peer review. Among these, the diagnosis initially given was wrong (27\%), imprecise $(50 \%)$ or significant information was added (23\%). The ability of nine expert clinicians to subcategorise the final diagnosis into the chILD-EU register classification had an overall exact inter-rater agreement of $59 \%$ on first assessment and after training, $64 \%$. Only $10 \%$ of the 'wrong' answers resulted in allocation to an incorrect category. Subcategorisation proved useful but training is needed for optimal implementation.

Conclusions We have shown that chILD-EU has generated a platform to help the clinical assessment of chILD.

Trial registration number Results, NCT02852928.

\section{Check for updates}

To cite: Griese M, Seidl E, Hengst $M$, et al. Thorax 2018:73:231-239.

\section{INTRODUCTION}

Children's interstitial lung diseases (chILD) is an umbrella term covering many rare conditions, frequently not diagnosed because the presentation is non-specific; and many entities which are

\section{Key messages}

What is the key question?

- Can an international management platform for children's interstitial lung disease (chILD) with independent multidisciplinary review be implemented and is the diagnostic subclassification reproducible?

What is the bottom line?

- Well-functioning, web-based multidisciplinary teams were successfully set up and significantly changed $13 \%$ of the diagnoses submitted by paediatric pneumologists. Subclassification by review-teams proved useful although training in implementation is needed.

Why read on?

- So you can learn how the system works and use it in the future.

ill- defined or poorly studied. Chest imaging shows diffuse abnormalities and age-appropriate lung function tests are abnormal. The incidence of these rare diseases in Europe is 0.5 to 1 cases in 100.000 . In the UK and Ireland, prevalence was estimated as 3.6 per million children ${ }^{1}$ and in Germany at 1.32 new cases per 1 million children/year. ${ }^{2}$ Prevalence and incidence is likely greatly underestimated due to misdiagnosis, lack of an ICD code allowing hospital based estimates of cases and the absence of a common register. Extrapolation to Europe (about 500 million people, 80 million children $<14$ years) suggests there are about 2000 known cases and an incident case rate of more than 100 per year. The overall mortality in childhood is around $15 \%{ }^{2}$ There are no evidence-based treatments for any of the diseases. ${ }^{3}$

The experiences of physicians, as well as the relatives and the patients, who often have been through a real diagnostic odyssey, show that these patients often do not receive optimal care. ${ }^{4}$ Progress is also 
very slow because of lack of technical resources for obtaining second opinions in complex individual cases and the absence of the sort of large, well-characterised cohorts which are essential for the conduct of randomised clinical trials. In paediatric oncology similar problems were solved decades ago as registries for diagnosis, systematic treatment plans and sufficient financial support were established. ${ }^{5}$ In paediatric respiratory medicine, cystic fibrosis has led the way from simple registries to the establishment of clinical trial networks. ${ }^{6}$ Networks have also been established for primary ciliary dyskinesia. ${ }^{7}$

In chILD, there is a pressing need for both specialised diagnostic advice from international experts because of the rareness of individual diagnoses and services to provide local care and therapy. Our objective was to implement an international management platform with independent multidisciplinary review of cases at presentation for long-term follow-up, to test if this would allow for more accurate diagnosis and thus provide structures for randomised controlled trials of treatment and translational studies. We here describe how we made such a platform and the chILD cases accumulated over a 3-year period. The outcomes from an expert review process are reported, together with assessment of the intraobserver consistency of expert reviewers, to help identify training requirements for clinical experts. We intend that this report will serve as a model for others setting up registries and biobanks across Europe in other diseases and disciplines.

\section{METHODS}

\section{Rationale and need for the chILD register}

The international registry for chILD was established to fill the previously unmet need of an international platform to systematically collect data from paediatric patients and allows all groups of professional and private stakeholders to participate in the care of patients with chILD. The registry governance fulfils the widely varying legal, data protection and ethical requirements across Europe, without compromising access to the data.

\section{Eligibility criteria, consent and ethical approval}

Patients are identified by their local physicians, who can register as participants in a referring centre. Any referring centre needs to ensure compliance with all necessary contractual legal and ethical requirements. The central register support team assists throughout this process. Each patient and/or caregiver gave respectively age-appropriate assent and written informed consent before any data were entered. The register and biobank study was approved by the responsible external lead ethics board, the Ethical Review Committee of the Ludwig-Maximilians University Munich, Germany (EK 111-13). The data safety protection processes of the register and biobank was approved by the Telematic Platform, an organisation for networked medical research. chILD was defined as entities originating from abnormalities of components of the lung parenchyma, which include the alveolar epithelium, vascular endothelium, interposed connective tissues and more centrally, the peribronchiolar and peribronchial tissues; airways may be involved as a secondary process. ${ }^{8}$ chILD was suspected if there were (1) respiratory symptoms/ signs such as cough, tachypnoea or dyspnoea at rest or with exercise, crackles, retractions, clubbing, failure to thrive, respiratory failure, (2) systemic arterial hypoxemia, (3) diffuse radiological abnormalities and if both feasible and available (4) abnormalities in pulmonary function testing, usually for a minimum duration of 4 weeks, but shorter in cases of acute severe chILD (usually neonatal onset), in accord with standard practice. ${ }^{910}$ We included all suspected chILD. ${ }^{11}$ A case not confirmed as chILD after peer review could be followed as a disease control. All patients included were prospectively and longitudinally followed. Baseline was the time of inclusion into the register; both prevalent cases which were already under review at the inception of the platform and incident, newly diagnosed cases were followed. During follow-up, suitable patients with chILD in the register study were eligible to enter randomised controlled trials set up in the Secutrial database, if consent was given.

\section{Minimal dataset and workflows of operation}

Cases were entered into the register using minimal dataset (generation and database dictionary (see online supplementary file 1 and table s1), peer-reviewed, categorised ${ }^{12}$ and followed over time. Automatic reminders were sent if follow-up was due. Communication on cases was strictly within the database using a discussion tool automatically embedding the local physician, the peer reviewers and additional experts if wished, in order to pool information without compromising security.

\section{Data safety concept, database and biobank}

In accord with best practice data protection (http://www.tmfev.de/EnglishSite/Home.aspx), there is an institutionally and organisationally separated storage of identifying (IDAT) and medical data (MDAT) (see online supplementary figure s1). The processing of the pseudonymised medical data is using SecuTrial, which is US Food and Drug Administration (FDA)-compliant and is concordant with good clinical practice rules. An additional SecuTrial-database for managing biomaterials is the central biobank at Munich University Hospital (see online supplementary figure s2).

\section{Quality control}

The register manager and register physicians carefully audit data completeness and score the quality of imaging and histological studies. Early in the project, the standards working group generated consensus-agreed diagnostic and management clinical guidelines. ${ }^{13}$ Due to shortage of resources, no source data verification is currently in place. In addition to immediate individual feedback to the centres via the national coordinator, annual reports are generated for each centre and the register.

\section{Peer review}

A central novel element of the register was the involvement of a multidisciplinary team review board. Although this is routine in adult ILD, ${ }^{14}$ until now this has not been routine in Europe in chILD. The goal of peer review was to give advice on diagnosis and differential diagnosis, to ensure adherence to diagnostic standards set previously,${ }^{13}$ to have a case review independent of the submitting centre, to use a harmonised categorisation system $^{12}$ and to come up with a final working diagnosis. Peer review teams were composed of a respiratory paediatrician, a paediatric radiologist and pathologist; if necessary, a geneticist was also consulted. The teams were constituted first on a national basis to establish the workflow within the management platform and then rolled out as an international resource. For online training, Skype conferences with shared screen features were organised. Peer review was started as soon as all relevant clinical data, imaging (see online supplementary file 1) and histology glass slides were available for the reviewers.

To assess the skills of categorisation of the final working diagnosis by clinicians, we randomly selected 25 chILD cases (from the first 312 cases peer-reviewed) with a pulmonary and 


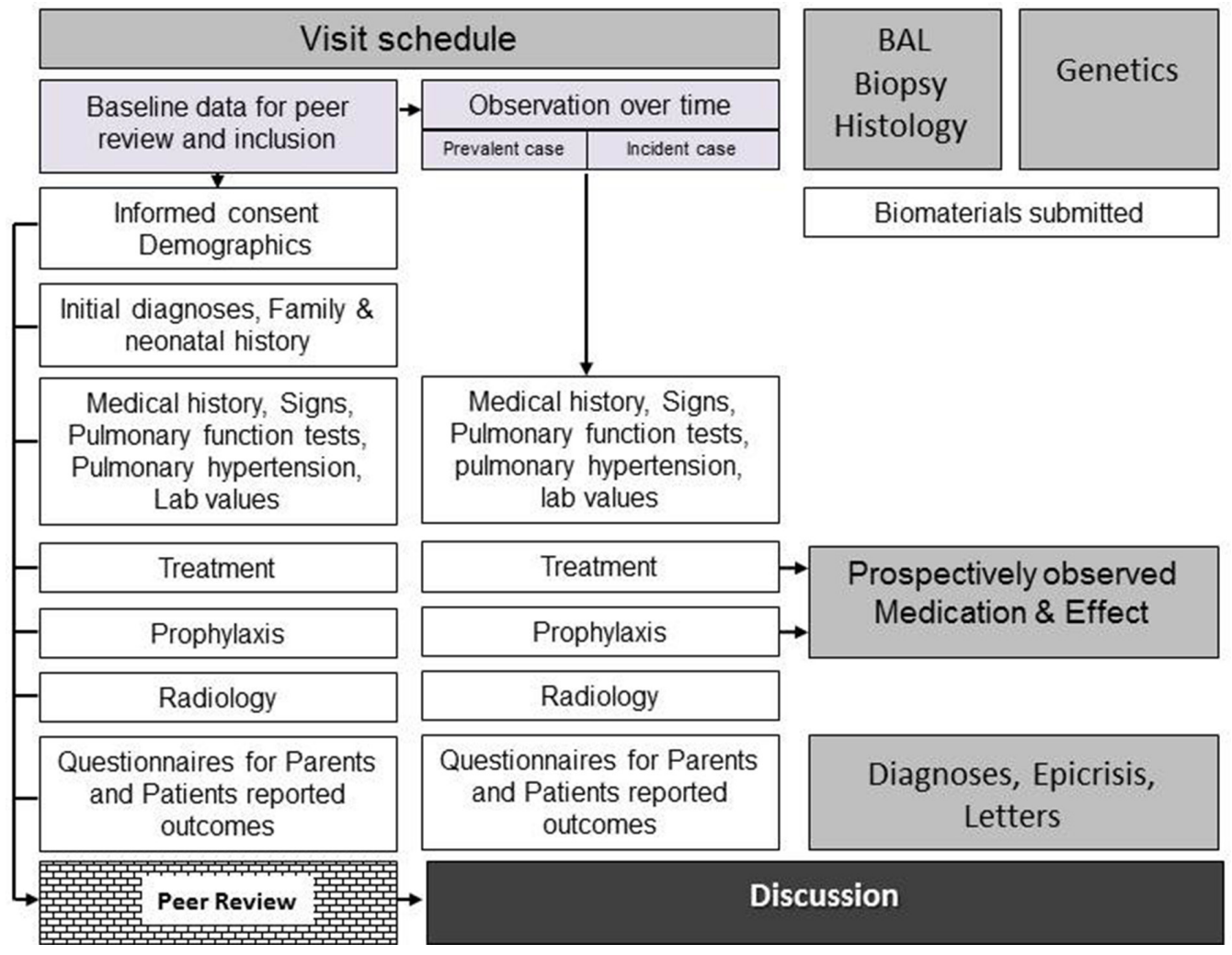

Figure 1 Management platform. BAL, bronchoalveolar lavage.

non-pulmonary diagnosis to be allocated to one of five given subcategories (see online supplementary table s2). The correct selection was determined by a group of three paediatric pneumologists who were very familiar with the categorisation system and strictly adhered to the previously set up categorisation rules. $^{12}$ The test took about $30-45 \mathrm{~min}$. Nine paediatric pneumologists with long-standing experience and interests in chILD were asked to subcategorise, and this test was repeated after 3 months. In between, a video and interactive training 'How to categorise chILD' was used for teaching.

\section{RESULTS \\ Register design-how the chILD-EU management platform works}

After registration of the local physician, an educational and interactive training session is undertaken. When familiar with the system, the physician or coordinator enters the web-based site to set up a new patient and enter the minimal dataset necessary for peer review. This includes a structured referral letter and imaging. Individual support for data entry by the central registry is offered. Great care is taken to pseudonymise uploaded letters and reports, and radiological images are automatically pseudonymised during upload (see online supplementary figure $\mathrm{s} 1$ ).

Baseline data include the entire past clinical course of the patient until entry into the database (figure 1, left column). chILD-specific patient reported outcomes were developed and validated and together with developmentally adapted versions for different age groups now available on the chILD platform in different languages (for details, see online supplementary file 1) as is information on health-economic status. Data obtained on a single occasion, such as biopsy, lavage and genetics, and prospective observations of specific treatments are entered separately (figure 1, right column). Information is exchanged and saved between local physician, data manager and peer reviewer via emails dispatched from the system and a discussion panel. Following review, diagnosis and categorisation (see below), the patient is observed prospectively over time with entry of a limited dataset (figure 1, middle column).

Material sent for central biobanking is indicated in the patient dataset with a collection number, so that local physician can track material associated with each subject. Site staff at central biobank record what has been sent with a collection identifier, so they can track materials. Biomaterials are entered into the separately run biobank. The material remains the property of the patient and/or family all the time.

\section{Enrolment and demography}

From January 2014 to November 2016, 575 patients (53\% male) from 82 centres in 16 countries were enrolled in the database (table 1). The median age of the children at inclusion was 5.5 years (range $0-25$; mean 7.0, SD 6.3 ) with an almost even distribution over time.

\section{Peer review of cases to establish final working diagnosis, disease category and subcategory}

When a peer review has been requested, the national coordinating team receives a message with an embedded link to the case, checks for completeness of data and materials and decides if the review process can be started or not (figure 2A). During the review meeting, the clinician presents the case using the referral letter; the images are demonstrated by the radiologists and the pathological review when relevant material is available is also presented. When needed, genetic advice is also taken. After discussion, the lead clinician summarises the diagnosis, categorises the case and concludes 
Table 1 Number of subjects included with country indicated and peer reviews done (status: 31 November 2016)

\begin{tabular}{lcccc}
\hline & $\begin{array}{l}\text { Number of subjects } \\
\text { included with } \\
\text { country indicated }\end{array}$ & $\begin{array}{l}\text { Country } \\
(\%)\end{array}$ & $\begin{array}{l}\text { Final peer } \\
\text { review done (n) }\end{array}$ & $\begin{array}{l}\text { Peer reviews } \\
\text { done (\%) }\end{array}$ \\
\hline Germany & 243 & 42.3 & 158 & 65.0 \\
\hline Italy & 22 & 3.8 & 10 & 45.5 \\
\hline Turkey & 55 & 9.6 & 47 & 85.5 \\
\hline UK & 103 & 17.9 & 65 & 63.1 \\
\hline France & 41 & 7.1 & 19 & 46.3 \\
\hline Belgium & 4 & 0.7 & 1 & 25.0 \\
\hline Brazil & 2 & 0.3 & 1 & 50.0 \\
\hline Croatia & 1 & 0.2 & 1 & 100 \\
\hline Denmark & 9 & 1.6 & 8 & 88.9 \\
\hline Netherlands & 2 & 0.3 & 1 & 50.0 \\
\hline Poland & 28 & 4.9 & 23 & 82.1 \\
\hline South Africa & 3 & 0.5 & 1 & 33.3 \\
\hline Spain & 4 & 0.7 & 2 & 50.0 \\
\hline Switzerland & 7 & 1.2 & 6 & 85.7 \\
\hline Austria & 5 & 0.9 & 1 & 20.0 \\
\hline Serbia & 1 & 0.2 & 0 & 0.0 \\
\hline Montenegro & & 7.8 & 2 & 4.4 \\
\hline Not indicated & 45 & 100.0 & 346 & 60.2 \\
\hline All & 575 & & & \\
\hline & & & & \\
\hline
\end{tabular}

the peer review. An automatic message informs the site physician about the result and further recommendations.

\section{Results from peer reviewing by multidisciplinary review teams}

Of the 575 patients included into the register for observation, 190 patients had insufficient data precluding the start of the peer review. In 385 patients, peer review requests were accepted, 39 could not be finalised due to information for which the reviewers asked but was not forthcoming (figure 2B) and a total of 346 peer reviews completed. These were done by teams in Munich $(\mathrm{n}=176 ; 51 \%)$, London $(\mathrm{n}=43,12 \%)$, Hannover $(\mathrm{n}=107$, $31 \%)$, Ankara $(\mathrm{n}=2 ; 1 \%)$ and Paris $(\mathrm{n}=18 ; 5 \%)$. Forty-six per cent of the cases had genetic testing (in 13\%, a final genetic diagnosis was made) and $43 \%$ a histopathology sample at the time of peer review. Both were not required for review, but may be recommended by the reviewers. In $87 \%$, the initial diagnosis given by the submitting paediatric pneumologist was confirmed by peer review (table 2). Among the 44 cases with their diagnosis altered by peer review, the diagnosis was wrong in $27 \%$, in $50 \%$ it was too general and in $23 \%$ significant information was added (table 2) (for detailed cases, see online supplementary table 2). The respecification of the diagnosis from peer review in conditions categorised as chILD occurring primarily in infancy ('A' groups in online supplementary table s3) was mainly due to knowledge from pathology review (20 of 44 cases) and genetics (seven cases), whereas in chILD conditions occurring at all ages ('B' groups in online supplementary table s3) radiological imaging and clinical review had the biggest impact. The age distribution of the children peer-reviewed had an initial peak in the first 2 years of life and an almost even distribution towards early adulthood (see online supplementary figure s3). Although changes in therapy were usually not recommended by peer review, we observed changes made in the majority of cases with an altered diagnosis (figure 3 and online supplementary table s3).

Overall, the spectrum of chILD categories and subcategories observed was broad, the majority of the patients coming from conditions more prevalent in infancy, that is, categories A3 and A4 and DPLD-related to systemic disease processes (table 3). The times to peer review acceptance and to peer review completion was very variable, which was mainly due to the need to retrieve missing information and communication delays (table 2). Some of the cases peer-reviewed entered the randomised controlled trial on hydroxychloroquine run by this platform (see online supplementary file 1 ).

\section{Ability of clinicians to subcategorise the final working diagnosis in the classification system used by the chILD-EU register}

This was tested in a collection of 25 complex chILD cases. In the first round, none of the cases was subcategorised correctly by any of the nine experts, whereas in the second round and after training there was a significant improvement of correct categorisation (figure 4, upper panel). The overall exact agreement of the nine experts in the first round was 59\% (free marginal kappa 0.19 ) and in the second round $64 \%$. This seems to be a relatively low inter-rater agreement; however, it must be considered that of the $225(25 \times 9)$ answers received, for example, in first round, a total of 54 were incorrect of which $23(10 \%$ of all answers) resulted in allocation to a false category and 31 merely in a wrong subcategory.

The many other important lessons which we have learnt during the project are listed in box 1 .

\section{DISCUSSION}

Here, we report details on the successful design and implementation of a web-based chILD management platform. We showed that it was feasible and practical to develop a European registry and biobank based for independent and multidisciplinary review of chILD, leading to protocolised follow-up and the setting up of randomised controlled trials. Our experiences may be a useful model for those setting up registries and biobanks across Europe in other fields. Specifically, we also detail the results on the subclassification of chILD diagnoses, the consequences of peer reviewing and the spectrum of the cases accumulated over a 3 -year period.

The chILD-EU project has linked national, European and international respiratory and general paediatricians, patients and parents groups, radiologists, pathologists, geneticists, translational and clinical scientists. The platform is an open resource for interested individuals and institutions. We have proposed diagnostic pathways of chILD ${ }^{13}$ which were implemented here, and we have established and harmonised peer review to actively help participating physicians with the diagnosis and treatment of their cases. In 44 cases, the diagnosis was altered by peer review and substantial changes in treatment were observed. Making a correct and independently peer-reviewed final working diagnosis in rare diseases is of importance for several reasons. First, the treating local physician may receive help or guidance during the diagnostic work-up, which may translate into more appropriate treatment. Second, both the physician and the family are reassured; these conditions are so rare that even big centres will not see enough always to be confident, and sharing cases can increase expertise across Europe. This may have important psychosocial and prognostic consequences. Third, 

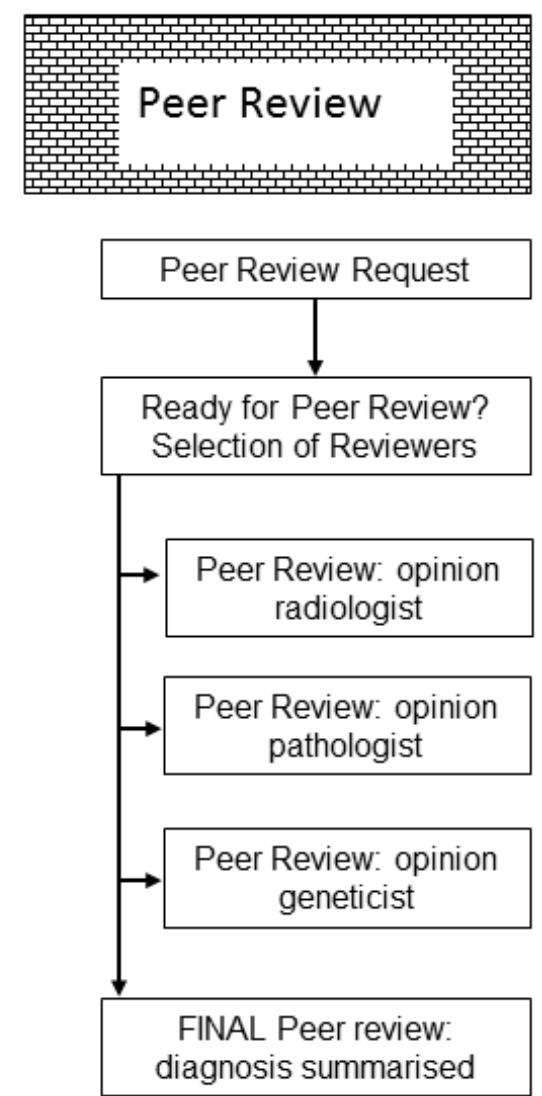
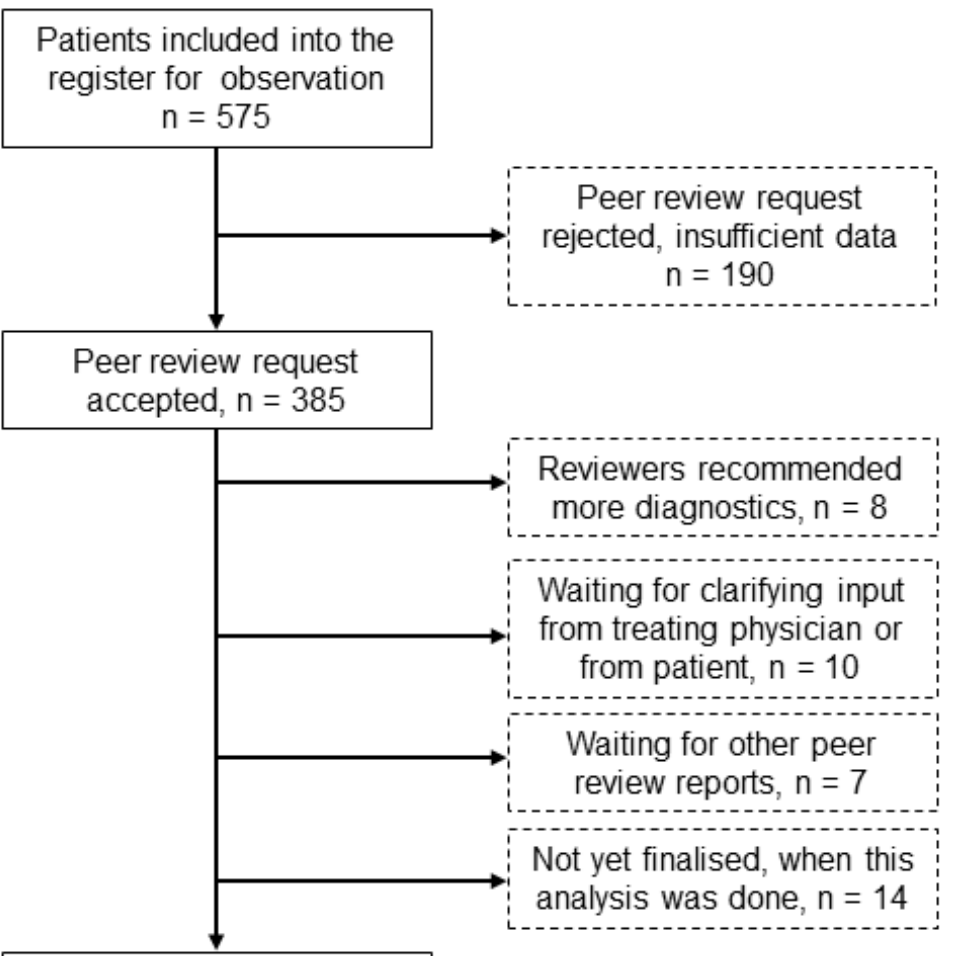

Peer reviews completed $n=346$

Figure 2 Peer review process in the chILD-EU register. (A) On peer review request by the local site physician, completeness of data is checked and if so, peer reviewers are selected and asked via emails from the system to start reviewing. The clinician peer reviewer prepares and presents the case in a common meeting, either in person or web-based with shared screen in internationally composed multidisciplinary teams. After completion, the clinician peer reviewer generates a final peer reviewer (working) diagnosis and subcategorises the diagnosis. The local site physician is informed via a mailing from the system about the conclusion of the review. (B) Consort diagram detailing patient flow during peer review process.

\begin{tabular}{|c|c|c|}
\hline & $\begin{array}{l}\text { Number of } \\
\text { cases }\end{array}$ & Percentage \\
\hline $\begin{array}{l}\text { No change from initial diagnosis to peer review } \\
\text { diagnosis }\end{array}$ & 302 & $87 \%$ \\
\hline $\begin{array}{l}\text { Change from initial diagnosis to peer review } \\
\text { diagnosis }\end{array}$ & 44 & $13 \%$ \\
\hline Initial diagnosis was wrong=>corrected ${ }^{*}$ & 12 & $27 \%$ \\
\hline $\begin{array}{l}\text { Initial diagnosis was too general=>specified final } \\
\text { diagnosis givent }\end{array}$ & 22 & $50 \%$ \\
\hline $\begin{array}{l}\text { Initial diagnosis was } \\
\text { incomplete=>relevantinformation added } \neq\end{array}$ & 10 & $23 \%$ \\
\hline $\begin{array}{l}\text { Time from peer review request until acceptance } \\
\text { (days) }\end{array}$ & $\begin{array}{l}\text { Median, mean } \\
\text { (range) }\end{array}$ & $\begin{array}{l}1 ; 30.5 \\
(0-746)\end{array}$ \\
\hline $\begin{array}{l}\text { Time from peer review acceptance until } \\
\text { completion (days) }\end{array}$ & $\begin{array}{l}\text { Median, mean } \\
\text { (range) }\end{array}$ & $\begin{array}{c}37 ; 67.5 \\
(0-803)\end{array}$ \\
\hline
\end{tabular}

Complete changes from peer-review are listed in Tab S3; typical examples are:

*'Postinfectious bronchitis obliterans' was changed to 'Neuroendocrine cell hyperplasia of infancy'.

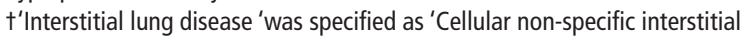
pneumonitis due to SFTPC mutation'.

¥'Alveolar capillary dysplasia without misalignment of the pulmonary veins' was changed to 'Alveolar capillary dysplasia without misalignment of the pulmonary veins and associated pulmonary interstitial glycogenosis PIG'. for the register and biobank, it is of great importance to have a reliable diagnosis and categorisation, to allow specific longterm follow-up and ensure only children with an appropriate diagnosis are entered into randomised controlled trials. Here, we have organised for the first time an easily accessed system tapping in to international expertise and described the activities since inception. The biggest hurdle for peer review is the local site physician who frequently lacks the time and resources to complete cases which were partially submitted, as indicated by

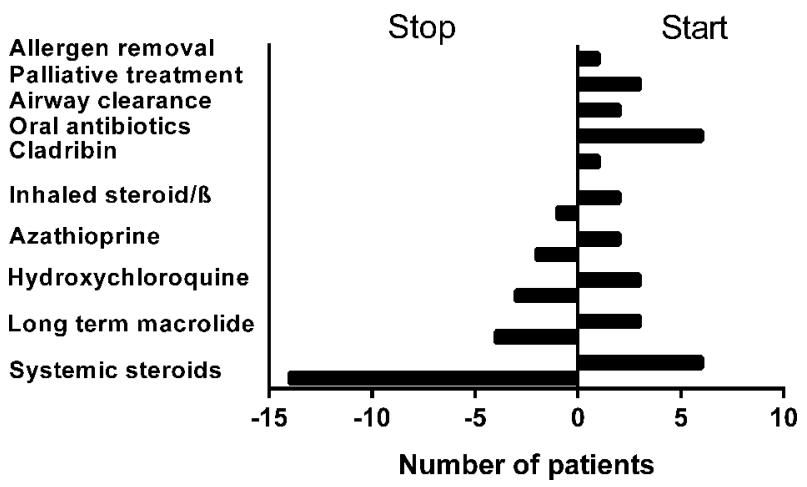

Figure 3 Changes in therapy observed after peer review in those 44 patients in whom the diagnosis was altered by peer review. 
Table 3 Distribution of 346 subjects in the disease categories and subcategories of the chILD-EU register after peer review

\begin{tabular}{|c|c|c|c|}
\hline Category & Subcategory/Diagnosis & Total & Percentage \\
\hline \multirow{3}{*}{$\begin{array}{l}\text { A1-DPLD-diffuse } \\
\text { developmental disorders }\end{array}$} & & 9 & $2.6 \%$ \\
\hline & $\begin{array}{l}\text { Alveolar capillary dysplasia } \\
\text { with misalignment pulmonary } \\
\text { vein }\end{array}$ & 7 & \\
\hline & Congenital alveolar dysplasia & 2 & \\
\hline \multirow{4}{*}{$\begin{array}{l}\text { A2-DPLD-growth } \\
\text { abnormalities deficient } \\
\text { alveolarisation }\end{array}$} & & 22 & $6.4 \%$ \\
\hline & Related to preterm birth & 11 & \\
\hline & $\begin{array}{l}\text { Related to chromosomal } \\
\text { disorders }\end{array}$ & 8 & \\
\hline & Others & 3 & \\
\hline \multirow{5}{*}{$\begin{array}{l}\text { A3-DPLD-infant } \\
\text { conditions of undefined } \\
\text { aetiology }\end{array}$} & & 64 & $18.5 \%$ \\
\hline & $\begin{array}{l}\text { Chronic tachypnoea of infancy } \\
\text { (usual or aberrant) }\end{array}$ & 30 & \\
\hline & $\begin{array}{l}\text { Neuroendocrine cell } \\
\text { hyperplasia of infancy }\end{array}$ & 27 & \\
\hline & $\begin{array}{l}\text { Pulmonary interstitial } \\
\text { glycogenosis }\end{array}$ & 5 & \\
\hline & Others & 2 & \\
\hline \multirow{7}{*}{$\begin{array}{l}\text { A4-DPLD-related to } \\
\text { alveolar surfactant region }\end{array}$} & & 77 & $22.3 \%$ \\
\hline & ABCA3 mutations & 18 & \\
\hline & SFTPC mutation & 10 & \\
\hline & NKX2.1 mutations & 3 & \\
\hline & NSIP & 19 & \\
\hline & Pulmonary alveolar proteinosis & 9 & \\
\hline & Others & 18 & \\
\hline $\begin{array}{l}A x-D P L D \text {-unclear RDS in } \\
\text { the mature neonate }\end{array}$ & & 5 & $1.4 \%$ \\
\hline $\begin{array}{l}\text { Ay-DPLD-unclear RDS in } \\
\text { the almost ( } 30-36 \text { weeks) } \\
\text { mature neonate }\end{array}$ & & 9 & $2.6 \%$ \\
\hline \multirow{10}{*}{$\begin{array}{l}\text { B1-DPLD-related to } \\
\text { systemic disease processes }\end{array}$} & & 54 & $15.6 \%$ \\
\hline & Sarcoidosis & 12 & \\
\hline & $\begin{array}{l}\text { Idiopathic pulmonary } \\
\text { haemosiderosis }\end{array}$ & 6 & \\
\hline & Storage diseases & 4 & \\
\hline & $\begin{array}{l}\text { Immune-mediated/collagen } \\
\text { vascular disorders }\end{array}$ & 4 & \\
\hline & Familial dysautonomia & 3 & \\
\hline & Filamin A mutation & 3 & \\
\hline & Langerhans cell histiocytosis & 3 & \\
\hline & $\begin{array}{l}\text { GPA_Granulomatosis with } \\
\text { polyangiitis (Wegener) }\end{array}$ & 3 & \\
\hline & Others & 16 & \\
\hline $\begin{array}{l}\text { B2-DPLD-in the presumed } \\
\text { immune intact host, related } \\
\text { to exposures (infectious/ } \\
\text { non-infectious) }\end{array}$ & & 46 & $13.3 \%$ \\
\hline
\end{tabular}

Continued
Table 3 Continued

\begin{tabular}{|c|c|c|c|}
\hline Category & Subcategory/Diagnosis & Total & Percentage \\
\hline & $\begin{array}{l}\text { Infectious/postinfectious } \\
\text { processes }\end{array}$ & 17 & \\
\hline & BO & 14 & \\
\hline & $\begin{array}{l}\text { Exogen allergic alveolitis/ } \\
\text { hypersensitivity pneumonitis }\end{array}$ & 7 & \\
\hline & Others & 8 & \\
\hline \multirow{5}{*}{$\begin{array}{l}\text { B3-DPLD-in the } \\
\text { immunocompromised host } \\
\text { or transplanted }\end{array}$} & & 15 & $4.3 \%$ \\
\hline & NSIP & 4 & \\
\hline & BO & 3 & \\
\hline & $\begin{array}{l}\text { Related to transplantation and } \\
\text { rejection }\end{array}$ & 3 & \\
\hline & Others & 5 & \\
\hline \multirow{4}{*}{$\begin{array}{l}\text { B4-DPLD-related to lung } \\
\text { vessels structural processes }\end{array}$} & & 16 & $4.6 \%$ \\
\hline & Pulmonary haemorrhage & 8 & \\
\hline & Pulmonary hypertension & 5 & \\
\hline & Others & 3 & \\
\hline \multirow{3}{*}{$\begin{array}{l}\text { B5-DPLD-related to } \\
\text { reactive lymphoid lesions }\end{array}$} & & 4 & $1.2 \%$ \\
\hline & $\begin{array}{l}\text { Lymphocytic interstitial } \\
\text { pneumonia }\end{array}$ & 3 & \\
\hline & Others & 1 & \\
\hline $\begin{array}{l}\text { Bx-DPLD-unclear RDS in } \\
\text { the NON-neonate }\end{array}$ & & 1 & $0.3 \%$ \\
\hline $\begin{array}{l}\text { By-DPLD-unclear NON- } \\
\text { neonate }\end{array}$ & & 5 & $1.4 \%$ \\
\hline $\mathrm{Bz}-\mathrm{DPLD}$ & & 1 & $0.3 \%$ \\
\hline $\begin{array}{l}\text { C1-localised, congenital } \\
\text { gross structural } \\
\text { abnormalities of the lungs }\end{array}$ & & 6 & $1.7 \%$ \\
\hline $\begin{array}{l}\text { C2-localised, acquired } \\
\text { gross structural } \\
\text { abnormalities of the lungs }\end{array}$ & & 0 & $0 \%$ \\
\hline \multirow[t]{3}{*}{ D-Airway disorders } & & 12 & $3.5 \%$ \\
\hline & Chronic bronchitis & 7 & \\
\hline & Others & 5 & \\
\hline
\end{tabular}

Cases of chronic tachypnoea of infancy (usual or aberrant) had no biopsy and were defined as described previously; ${ }^{16}$ cases were only labelled 'Neuroendocrine cell hyperplasia of infancy' if there was proof by biopsy and concordant clinical symptoms. Details on the classification system and definitions used are given in the supplement of Griese et al. ${ }^{12}$

BO, bronchiolitis obliterans; DPLD, diffuse parenchymal lung diseases; NSIP, nonspecific interstitial pneumonitis; RDS, respiratory distress syndrome.

the 190 patients with insufficient data precluding the start of the peer review. Although for the majority of cases the initial working diagnosis was confirmed by peer reviewers, there were significant changes of the final working diagnosis in nearly one in seven cases (see online Supplementary table s3), underpinning the pivotal role of peer review in paediatrics, as for adults with diffuse parenchymal lung disease. ${ }^{14}$ Future studies will address the reproducibility and precision of making the working diagnosis in chILD by multidisciplinary paediatric teams.

Categorisation and subcategorisation of a diagnosis is of great importance for any systematic register. Based on our previous 


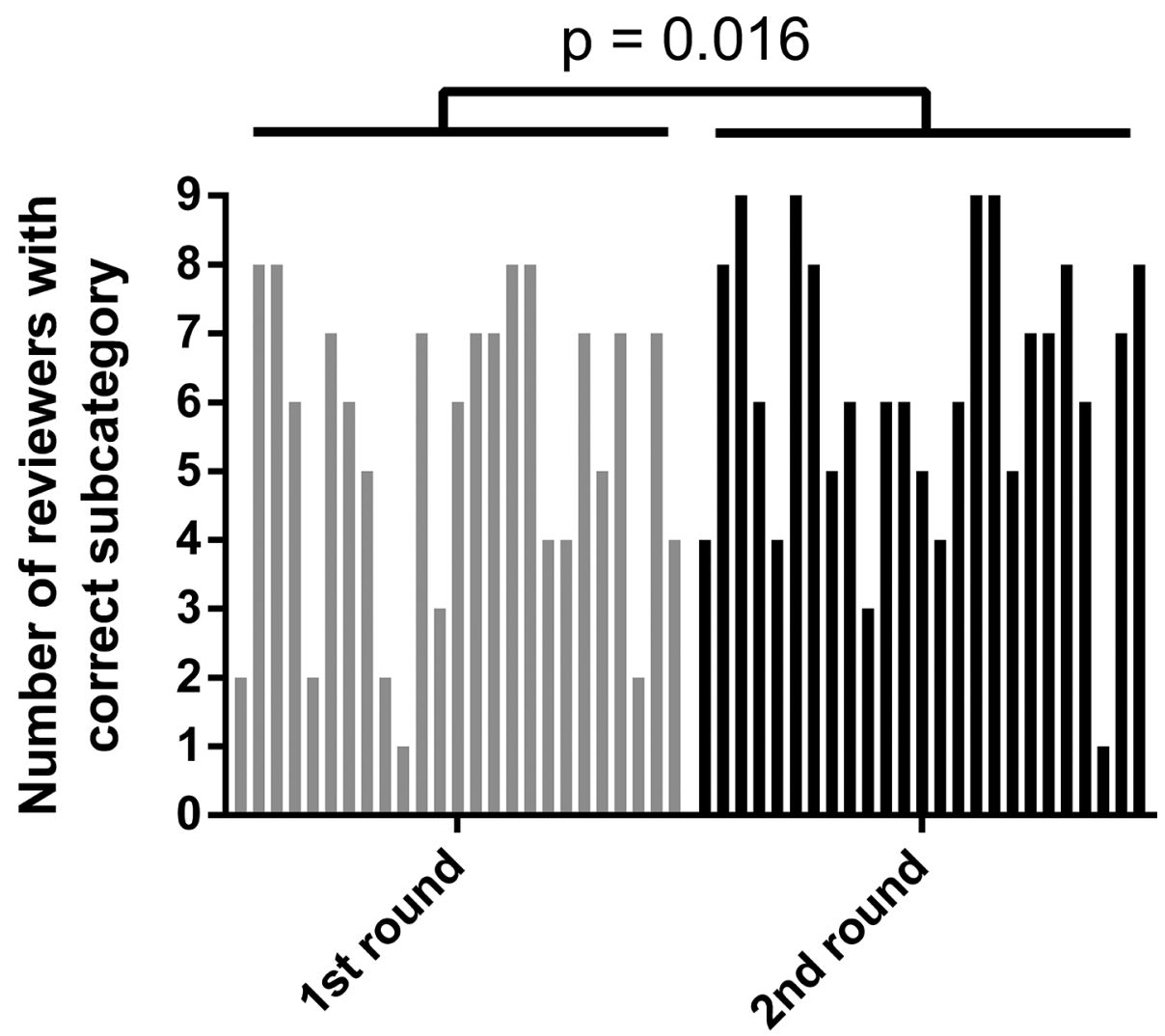

25 cases categorised in each round

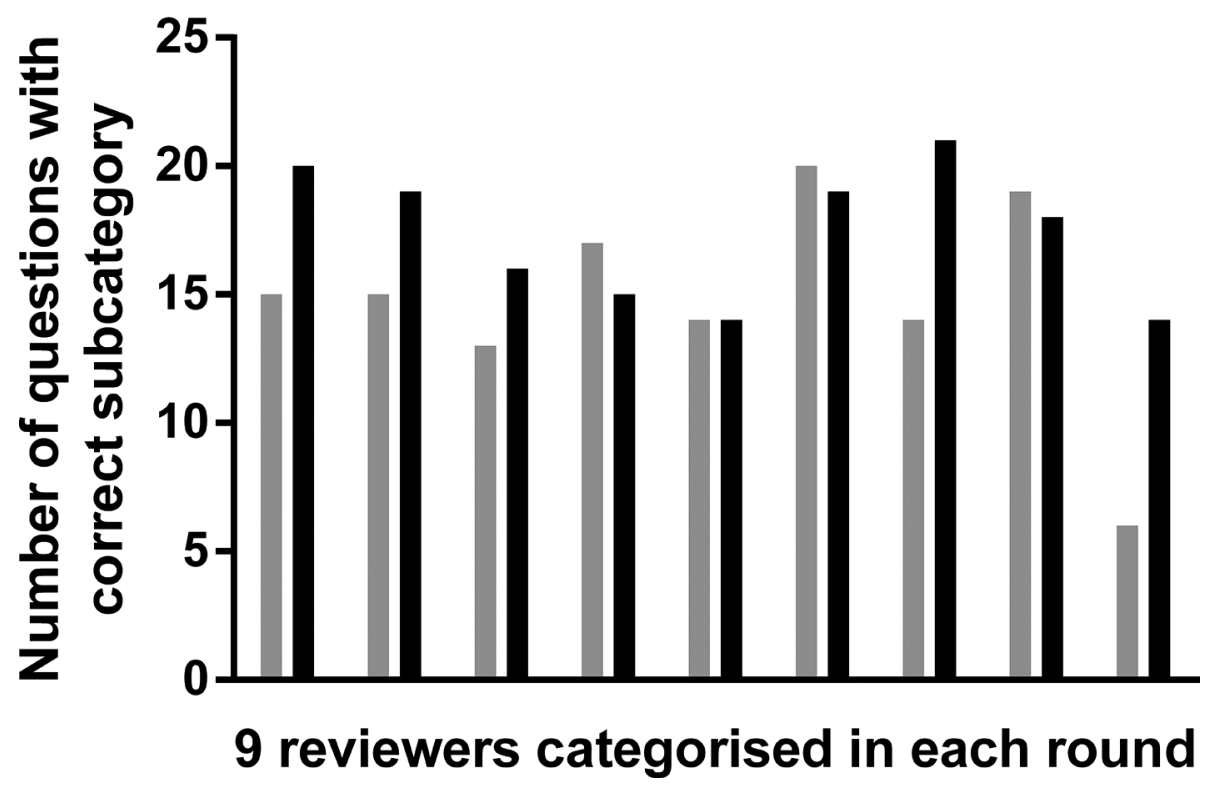

Figure 4 Selection of the correct subcategory from a panel of five suggestions each for 25 final working diagnoses by nine experienced paediatric clinical peer reviewers (see also online supplementary table s2). The upper panel shows the correct reviewers by question 1 to 25 in the first and second rounds. The latter was done after training using a video tutorial, web-based email-discussion of open issues and a personal meeting. The lower panel shows the responses of the individual peer reviewers before and after training. Responses of first and second round were compared by 2-sided paired t-test. The lower panel shows the responses of the individual peer reviewers before and after training.

local assessment of the reliability in chILD diffuse parenchymal disease and an average correct rate of $87 \%,{ }^{2}$ we were not surprised by the relatively low rate of correct categorisation (72\%) obtained from a large group of nine untrained experts. The number of cases put by individual reviewer into a wrong category was low (10\%). Nevertheless, in subcategorisation, a diagnosis is sometimes difficult and this needs to be further harmonised and practiced by the teams.

We are now studying the natural history of patients with chILD and will describe frequencies and variability of end-points 
Box 1 Practical advice from lessons learnt during work with the management platform

\section{All participants}

- Do not start peer review until all necessary information and materials on a case are collected

- Do not expect even after training that ability to work with the database is sustained without participants using it regularly

- Strictly keep communication on cases within the management platform

- Training in relatively complex procedures like uploading imaging should only be done in central/national sites, as technical details to be solved (eg, hospital firewalls) may otherwise be too time-consuming.

- Plan extensive time for local ethics applications and other local centre processes if a randomised controlled trial is contemplated

- Practical support to enter data should be supplied centrally including upload of imaging, digitising of letters, cutting of wax blocks, staining slides, upload of scans, shared screen guided support lessons, double entry of quality of life and other questionnaires and so on.

Peer reviewer/national coordinator

- Organisation of regular local conference sessions using active cases

- Explanation and exercises using the categorisation system

- Data manager and auditing staff

- Build a personal relation with site staff

- Always offer training and help regarding all aspects of the register

- Constantly collect, document and optimise (screenshot, explanation, suggested solutions) problems faced when working with the database

such as clinical scoring, pulmonary exacerbations, ${ }^{15}$ medication usage, hospitalisation rates, costs of care and quality of life; this would be impossible without this sort of platform. Importantly, we have commenced the first ever randomised, placebo-controlled interventions in chILD after overcoming all administrative hurdles in Germany and started to recruit peer-reviewed cases (www.childeu.net, see online supplementary file 1). We have a unique collective experience and have learnt many lessons in the day-to-day practicalities of running a register and biobank (see box 1).

chILD are difficult to study because nomenclature varies in a group of more than 200 entities, all of which are rare. Although diffuse parenchymal disease may more correctly describe the entities included, we adopted the acronym chILD in line with the statement of the American Thoracic Society in 2013. ${ }^{9}$ The chILD-EU project introduced the term in Europe and increased the awareness of chILD. The interaction between professionals and family groups across Europe has perhaps been the most important result of this initiative. Also of importance is the support of the growing chILD-EU group by the European Respiratory Society establishing a Clinical Research Collaboration and the European Union by the COST Action CA16125. Long-term follow-up of a large cohort of patients with chILD to learn about the natural history will be a major challenge in the future. Hurdles include access to funding to support clinicians faced with a big daily workload to ensure high-quality data continue to be entered into the register. Furthermore, the large administrative hurdles are a major barrier to investigator-initiated studies in rare diseases in Europe (see online supplementary discussion).

Taken together, the FP7 project chILD-EU has generated a solid basis for the comprehensive study of paediatric interstitial lung diseases. The platform is a stepping stone for future work. Many new tools were made available to improve the care of individual cases. Collectively, data are generated to describe simple and complex end-points, medication usage, and some centres were opened to perform randomised placebo-controlled interventions in chILD. In the future, much more diverse activities are envisioned including basic and translational mechanistic studies, epidemiological investigations and teaching activities, all of which would be impossible without a central registry.

\section{Author affiliations}

'Department of Pediatric Pneumology, Dr von Hauner Children's Hospital, Ludwig-

Maximilians-University, German Center for Lung Research, Munich, Germany

${ }^{2}$ Department of Pathology, LMU Munich, Munich, Germany

${ }^{3}$ Department of Neurology, University of Marburg, Central Information Office,

Marburg, Germany

${ }^{4}$ Division of Pediatric Pulmonology, Hacettepe University Faculty of Medicine, Ankara, Turkey

${ }^{5}$ Department of Pediatrics, University of Padova, Padova, Italy

${ }^{6}$ Child and Adolescent Psychiatry, University of Ulm, Clinic for Child and Adolescent Psychiatry/Psychotherapy, Ulm, Germany

${ }^{7}$ Helmholtz Zentrum München, Deutsches Forschungszentrum für Gesundheit und Umwelt, Munich, Germany

${ }^{8}$ Department of Pediatric Radiology, Dr von Hauner Children's Hospital, LudwigMaximilians-University, Munich, Germany

${ }^{9}$ Department of Respiratory and Sleep Medicine, Royal Hospital for Sick Children, Edinburgh, UK

${ }^{10}$ Department of Paediatrics, Royal Brompton Hospital, London, UK

${ }^{11}$ Department of Paediatrics, Imperial College London, NHLI, London, UK ${ }^{12}$ Department of Paediatrics, University Pierre und Marie Curie, Paris, France

${ }^{13}$ Department of Paediatrics, Great Ormond Street Hospital For Children NHS Trust, London, UK

${ }^{14}$ Department of Pediatric Pulmonology, Hannover Medical School, Hannover, Germany

Correction notice This article has been corrected since it was published Online First. Author note was included in error, so it has now been removed. Collaborator, N Cobanoglu's name was incorrect and is now corrected.

Acknowledgements We thank all the families and patients for their participation. The project would not have been possible with all the chILD-EU collaborators.

Collaborators chILD-EU collaborators are: E Eber (Universitätsklinikfür Kinderund Jugendheilkunde, Graz, Austria), A Pfleger (Universitätsklinik für Kinder- und Jugendheilkunde, Graz, Austria), P Basek (Kinderspital Salzburg, Austria), M Proesmans (UZ Leuven, Belgium), LV Ribeiro Silva Filho (Emergency Instituto daCriança do Hospital das Clínicas da FMUSP, Sao Paulo, Brasil), I Rochat (Centre hospitalier universitaire vaudois, Lausanne, Switzerland), M Fontana (Kinderspital Luzern, Switzerland), J Freihorst (Ostalb Klinikum, Aalen, Germany), F Brinkmann (RuhrUniversity-Bochum, Germany), C Koerner-Rettberg (RuhrUniversity-Bochum, Germany), S Becker (Darmstädter Kinderklinik Prinzessin Margaret, Darmstadt, Germany), F Stehling (University of Essen, Germany), A Heinzmann (Universitätsklinik Freiburg, Germany), S Kusserow (Marienhospital, Gelsenkirchen, Germany), L Nährlich (Universitätsklinikum Gießen und Marburg, Giessen, Germany), C Lex (Universitätsmedizin Göttingen, Germany), D Berthold (Medizinische Hochschule Hannover Zentrum für Kinderheilkunde und Jugendmedizin, Hannover, Germany), P Kaiser-Labusch (Gesundheit Nord Klinikverbund Bremen, Germany), S Hämmerling (Universitätsklinikum Heidelberg, Germany), F Ahrens (Altonaer Kinderkrankenhaus, Hamburg, Germany), S Müller-Stöver (Altonaer Kinderkrankenhaus, Hamburg, Germany), E Tutdibi (Universitätsklinikum des Saarlandes, Homburg, Germany), K Seidemann (Städtisches Klinikum Karlsruhe, Germany), F Prenzel (Klinik und Poliklinik für Kinder- und Jugendmedizin Universitätsklinikum Leipzig, Germany), K Reiter (Dr von Haunersches Kinderspital, München, Germany), M Feilcke (Dr von Haunersches Kinderspital, München, Germany), J Ripper (Dr von Haunersches Kinderspital, München, Germany), I Pawlita (Dr von Haunersches Kinderspital, München, Germany), I Fischer (Dr von Haunersches Kinderspital, München, Germany), S Witt (Helmholtz Zentrum München, Institute of Health Economics and Health Care Management, Neuherberg, Germany), L Schwarzkopf (Helmholtz Zentrum München, Institute of Health Economics and Health Care Management, Neuherberg, Germany), B L Szentes (Helmholtz Zentrum München, Institute of 
Health Economics and Health Care Management, Neuherberg, Germany), S Weichert (UMM Universitätsmed. Mannheim Klinik für Kinder- und Jugendmedizin, Mannheim, Germany), T Schaible (UMM Universitätsmedizin Mannheim Klinik für KinderundJugendmedizin, Mannheim, Germany), I Kern (Elisabeth-Krankenhaus Rheydt, Mönchengladbach, Germany), J Seidenberg (Zentrum fürKinder- und Jugendmedizin, Oldenburg, Germany), S Zeidler (Asklepios Kinderklinik, Sankt Augustin, Germany), W Baden (Universitätsklinik für Kinder- und Jugendmedizin Tübingen, Germany), M Niemitz (Universitätsklinikum Ulm Kinder- undJugendpsychiatrie, Ulm, Germany), M Gappa (Zentrum für Kinder undJugendliche-Marien-Hospital Wesel, Germany), J Liese (Universitätsklinikum Würzburg —Kinderklinik, Würzburg, Germany), S Rubak (Aarhus University, Denmark), F Buchvald (University ofCopenhagen, Denmark), PAlmario (Hospital Universitario Barcelona,Spain), A Escribano (SEPAR Sociedad Espanyola de Neumologia yCirurgia Toràcica, Valencia, Spain), J Lopez (Escuela Universitariade Enfermería La Fe, Valencia, Spain), A Coulomb (CHU Paris-EstHôpital d'Enfants Armand Trousseau, Paris, France), H Ducou LePointe (CHU Paris-Est Hôpital d'Enfants Armand Trousseau, Paris, France), N Nathan (CHU Paris-Est Hôpitald'Enfants Armand Trousseau, Paris, France), J Reiter (Hadassah-Hebrew University, Jerusalem, Israel), G Rossi (Giannina Gaslini, Genova, Italy), A Barbarto (University of Padova, Padova, Italy), P Cogo (Ospedale Pediatrico Bambino Gesù, Roma, Italy), S Terheggen-Largo (University Medical Center Utrecht, Netherlands), E Glowacka (Children's University Hospital, Krakow, Hungary), J Lange (Medical University of Warsaw, Poland), K Katarzyna (Medical University of Warsaw, Poland), N Cobanoglu (Ankara University, Ankara, Turkey), T Sismanlar (Gazi University Hospital, Ankara, Turkey), A T Aslan (Gazi University Hospital, Ankara, Turkey), D Orhan (Hacettepe University, Ankara, Turkey), O Berna (Hacettepe University, Ankara, Turkey), G Cinel (Hacettepe University, Ankara, Turkey), E Yalçın (Hacettepe University, Ankara, Turkey), F N Sair (Zekai Technical Hospital, Ankara, Turkey), C M Bal (Ege Üniversitesi, Izmir, Turkey), H Yuksel (Manisa Celal Bayar Üniversitesi, Turkey), S Turner (Royal Aberdeen Children's Hospital, UK), S Michael (Queen's University, Belfast, United Kingdom), P Kenia (Children's Hospital, Birmingham, UK), T Hilliard (Royal Hopital for Children, Bristol, UK), R Ross-Russell (Addenbrookes, Cambridge, UK), J Forton (University of Wales, Cardiff, Wales), F Redmond (Royal Hospital for Sick Children, Edinburgh, UK), N Gibson (Royal Hospital for Children, Glasgow, UK), C Wallis (Great Ormond Street Hospital, London, UK), R Pabry (Great Ormond Street Hospital, London, UK), C Owens (Great Ormond Street Hospital, London, United Kingdom), A Gupta (King's Colleage, London, UK), S Mayell (Royal Children's Hospital, Liverpool, UK), P Chetcuti (Leeds General Infirmary Children's Hospital, Leeds, UK), F Child (Royal Children's Hospital, Manchester, UK), S Moss (Royal Victoria Infirmary, Newcastle, UK), J Bhatt (Nottingham Children's Hospital, Nottingham, United Kingdom), J Hull (John Radcliffe Hospital, Oxford, UK), D Hansel (Royal Brompton Hospital, London, UK), C Nwokoro (Whitechapel Royal London Hospital, London, UK), R O'Reilly (Sheffield Children's Hospital, UK), W Walker (General Hospital, Southampton, UK), H Seidl (Helmholzzentrum, Munich, Germany), F Brasch (Institute for Pathology, Klinikum Bielefeld, Germany), C Gilbert (UK-chILDfoundation), M Zampoli (Red Cross Children's Hospital, Kapstadt, South Africa), F Kritzinger (Netcare Christiaan Barnard Memorial Hospital, Kapstadt, South Africa), M Rosewich (Olgahospital, Stuttgart, Germany).

Contributors MG designed the project, organised and developed the platform with register and biobank, reviewed the cases and performed calculations and data interpretation. He drafted the manuscript under the corrective action of AB. All authors reviewed the manuscript and agreed with the contents. HR and GA set up and programmed the web-based system. Clinical principal site investigators of the project were NK, DS, LG, RL, AC, RE, JDB, SC, NS, AB, MG. Major contributions for the Pediatric radiology group came from JL-Z, IK-S, BK and AC. Major contributions for the Pediatric pathology group came from SR, AM and AGN. TW, CE, AS, DN, MM and $M C L$ were key clinical trial management staff. Major additional clinical peer-review came from ES, MH, NE, PA, MW and MK. ES and MH were central register physicians. All authors participated in discussions for the development and conclusion of the project. All contributors listed supplied cases and participated in the cases-related discussions.

Funding The research leading to these results has received funding from the European Union's Seventh Framework Program under grant agreement n³05653-chILD-EU. Funding of the project started in December 2012 and ended in November 2016; the project is continuous under ClinicalTrials.gov identifier: NCT02852928.

Competing interests None declared.

Patient consent Obtained.

Ethics approval Ethics Committee of the University of Munich.

Provenance and peer review Not commissioned; externally peer reviewed.

(c) Article author(s) (or their employer(s) unless otherwise stated in the text of the article) 2018. All rights reserved. No commercial use is permitted unless otherwise expressly granted.

\section{REFERENCES}

1 Dinwiddie R, Sharief N, Crawford O. Idiopathic interstitial pneumonitis in children: a national survey in the United Kingdom and Ireland. Pediatr Pulmonol 2002;34:23-9.

2 Griese $\mathrm{M}$, Haug $\mathrm{M}$, Brasch $\mathrm{F}$, et al. Incidence and classification of pediatric diffuse parenchymal lung diseases in Germany. Orphanet J Rare Dis 2009;4:26.

3 Smyth AR, Barbato A, Beydon N, et al. Respiratory medicines for children: current evidence, unlicensed use and research priorities. Eur Respir J 2010;35:247-65.

4 Gilbert C, Bush A, Cunningham S. Childhood interstitial lung disease: family experiences. Pediatr Pulmonol 2015:50:1301-3.

5 Carbone PP, Tormey DC. Organizing multicenter trials: lessons from the cooperative oncology groups. Prev Med 1991;20:162-9.

6 De Boeck K, Bulteel V, Fajac I. Disease-specific clinical trials networks: the example of cystic fibrosis. Eur J Pediatr 2016:175:817-24.

7 Werner C, Lablans M, Ataian M, et al. An international registry for primary ciliary dyskinesia. Eur Respir J 2016;47:849-59.

8 The diagnosis, assessment and treatment of diffuse parenchymal lung disease in adults. Introduction. Thorax 1999;54(Suppl 1):S1-14.

9 Kurland G, Deterding RR, Hagood JS, et al. An official American Thoracic Society clinical practice guideline: classification, evaluation, and management of childhood interstitial lung disease in infancy. Am J Respir Crit Care Med 2013:188:376-94.

10 Nathan N, Taam RA, Epaud R, et al. A national internet-linked based database for pediatric interstitial lung diseases: the French network. Orphanet J Rare Dis 2012;7:40

11 Bush A, Anthony G, Barbato A, et al. Research in progress: put the orphanage out of business. Thorax 2013;68:971-3.

12 Griese $M$, Irnstetter $A$, Hengst $M$, et al. Categorizing diffuse parenchymal lung disease in children. Orphanet J Rare Dis 2015;10:122.

13 Bush A, Cunningham S, de Blic J, et al. European protocols for the diagnosis and initial treatment of interstitial lung disease in children. Thorax 2015;70:1078-84.

14 Walsh SL, Wells AU, Desai SR, et al. Multicentre evaluation of multidisciplinary team meeting agreement on diagnosis in diffuse parenchymal lung disease: a case-cohort study. Lancet Respir Med 2016;4:557-65.

15 Clement A, de Blic J, Epaud R, et al. Management of children with interstitial lung diseases: the difficult issue of acute exacerbations. Eur Respir J 2016;48:1559-63.

16 Rauch D, Wetzke M, Reu S, et al. Persistent tachypnea of infancy. usual and aberrant. Am J Respir Crit Care Med 2016;193:438-47. 